\title{
Evaluation of the effects of polymeric chitosan/tripolyphosphate and solid lipid nanoparticles on germination of Zea mays, Brassica rapa and Pisum sativum
}

\author{
Daniele Y. Nakasato $^{\mathrm{a}, 1}$, Anderson E.S. Pereira ${ }^{\mathrm{b}, 1}$, Jhones L. Oliveira ${ }^{\mathrm{a}}$, Halley C. Oliveira ${ }^{\mathrm{c}}$, \\ Leonardo F. Fraceto ${ }^{\mathrm{a}, \mathrm{b}, *}$ \\ a São Paulo State University (Unesp), Institute of Science and Technology, Sorocaba, Environmental Nanotechnology Lab, Avenida Três de Março, 511, CEP 18087-180 \\ Sorocaba, SP, Brazil \\ b Department of Biochemistry and Tissue Biology, State University of Campinas (UNICAMP), Campus Universitário Zeferino Vaz, s/n, Cidade Universitária, CEP 13083- \\ 870 Campinas, SP, Brazil \\ ${ }^{c}$ Departament of Animal and Plant Biology, State University of Londrina, PR $445 \mathrm{~km} 380$, CEP 86057-970 Londrina, PR, Brazil
}

\section{A R T I C L E I N F O}

\section{Keywords:}

Phytotoxicity

Nanoparticles

Chitosan

Solid lipid nanoparticles

Agriculture

\begin{abstract}
A B S T R A C T
Although the potential toxicity of many metallic and carbon nanoparticles to plants has been reported, few studies have evaluated the phytotoxic effects of polymeric and solid lipid nanoparticles. The present work described the preparation and characterization of chitosan/tripolyphosphate (CS/TPP) nanoparticles and solid lipid nanoparticles (SLN) and evaluated the effects of different concentrations of these nanoparticles on germination of Zea mays, Brassica rapa, and Pisum sativum. CS/TPP nanoparticles presented an average size of $233.6 \pm 12.1 \mathrm{~nm}$, polydispersity index (PDI) of $0.30 \pm 0.02$, and zeta potential of $+21.4 \pm 1.7 \mathrm{mV}$. SLN showed an average size of $323.25 \pm 41.4 \mathrm{~nm}$, PDI of $0.23 \pm 0.103$, and zeta potential of $-13.25 \pm 3.2 \mathrm{mV}$. Nanotracking analysis enabled determination of concentrations of $1.33 \times 10^{10}$ (CS/TPP) and $3.64 \times 10^{12}$ (SLN) nanoparticles per mL. At high concentrations, CS/TPP nanoparticles caused complete inhibition of germination, and thus negatively affected the initial growth of all tested species. Differently, SLN presented no phytotoxic effects. The different size and composition and the opposite charges of SLN and CS/TPP nanoparticles could be associated with the differential phytotoxicity of these nanomaterials. The present study reports the phytotoxic potential of polymeric CS/TPP nanoparticles towards plants, indicating that further investigation is needed on the effects of such formulations intended for future use in agricultural systems, in order to avoid damage to the environment.
\end{abstract}

\section{Introduction}

Nanomaterials possess unique properties that make them highly attractive for applications in various industrial sectors including pharmaceuticals, cosmetics, energy, and agriculture (Servin et al., 2015). Growth in the development of new applications for nanomaterials may result in the presence of these substances in the environment, where they could become included in the food chain of living organisms, resulting in effects such as bioaccumulation (Husen and Siddiqi, 2014). It is therefore necessary to understand the fates of nanomaterials in the environment, how they interact with living organisms, and the biological effects that they can cause (Part et al., 2015). In the environment, nanoparticles can reach the soil, water, and air, and plants are among the organisms most likely to be exposed to them (Larue et al., 2014; Ma et al., 2010). In particular, when nanoparticles are used as carrier systems for agrochemicals, plants are exposed to high concentrations of nanomaterials.

Studies have been conducted to obtain a better understanding of the biological effects of nanomaterials, as well as the mechanisms of their uptake and translocation in plants (Pérez-de-Luque et al., 2012). Physico-chemical characteristics of nanoparticles such as size, zeta potential, and concentration determine their interactions with plant cells and can influence the physiological responses (Thuesombat et al., 2014). Phytotoxic effects on plants include inhibition of germination, changes in the structure and development of the plant tissues, oxidative stress, and clastogenic effects (Chen et al., 2010; Rajeshwari et al.,

\footnotetext{
* Correspondence to: São Paulo State University, Av. Três de Março, 511, Alto da Boa Vista, CEP 18087-180 Sorocaba, São Paulo, Brazil.

E-mail address: leonardo@sorocaba.unesp.br (L.F. Fraceto).

${ }^{1}$ Authors contribute equally.
} 
2015). Studies have analyzed the effects on plants of carbon nanoparticles (Khodakovskaya et al., 2009), nanoparticles of titanium, zinc, copper, manganese, and iron oxides (Liu et al., 2016; Servin et al., 2012), silver nanoparticles (Larue et al., 2014), and gold nanoparticles (Zhu et al., 2012). Other types of nanoparticles with potential agricultural applications are polymeric and lipid nanoparticles, which can be employed as delivery systems for nutrients and pesticides in the field (Campos et al., 2014; Kashyap et al., 2015). In studies of the biological activities of systems consisting of poly(epsilon-caprolactone) nanoparticles (Pereira et al., 2014) and solid lipid nanoparticles (de Oliveira et al., 2015), it was observed that nanoparticles without herbicide loadings in pre-emergent studies presented phytotoxic effects at high concentrations on the plant species Brassica sp. and Raphanus raphanistrum, respectively. However, no phytotoxic effects were observed in postemergence treatment of Brassica sp. and Zea mays with unloaded poly(epsilon-caprolactone) nanoparticles (Oliveira et al., 2015a, 2015b). These studies have shown the importance to evaluate polymer or lipid-based nanocarrier systems in relation the phytotoxic effects on seed germination and seedling development of different plant species in order to propose concentrations of these nanoparticles for safe future applications in the field.

The present work evaluates the effects that nanoparticles of chitosan/tripolyphosphate (CS/TPP) and solid lipid nanoparticles (SLN) cause on plant development. It concerns the production and characterization of CS/TPP nanoparticles and SLN, without loading of active chemical, with evaluation of the effects of different concentrations on three different plant species (Zea mays, Brassica rapa, and Pisum sativum) in order to identify possible phytotoxic effects on germination and seedling development.

\section{Material and methods}

\subsection{Materials}

The reagents chitosan (MW $27 \mathrm{kDa}$, degree of deacetylation: 75-85\%), tripolyphosphate, glyceryl tripalmitate and polyvinyl alcohol were obtained from Sigma-Aldrich. The seeds of Zea mays, Brassica rapa and Pisum sativum were purchased from ISLA Sementes.

\subsection{Methods}

\subsubsection{Preparation of the nanoparticles}

CS/TPP nanoparticles were prepared by the ionotropic pre-gelation method proposed by Calvo et al. (1997), with modifications. A $6 \mathrm{~mL}$ volume of tripolyphosphate (TPP) solution $(0.1 \%, \mathrm{pH} 4.5)$ at $4{ }^{\circ} \mathrm{C}$ was slowly added over a solution of CS $(0.2 \%)$ diluted in acetic acid $(0.6 \%$, $\mathrm{pH}$ 4.7), under agitation. After addition of TPP, the mixture was kept under vigorous agitation for $40 \mathrm{~min}$.

SLN were prepared according to the methodology proposed by Vitorino et al. (2011) Firstly, $5 \mathrm{~mL}$ of an organic solution of chloroform containing glyceryl tripalmitate $(75 \%)$ were added to $30 \mathrm{~mL}$ of an aqueous solution of polyvinyl alcohol $(0.6 \%)$, followed by sonication for $5 \mathrm{~min}$ at $40 \mathrm{~W}$. The pre-emulsion formed was subjected to ultraturrax agitation for $7 \mathrm{~min}$. The solvent was removed using a rotary evaporator, and the final solution volume was $20 \mathrm{~mL}$.

\subsubsection{Characterization of the nanoparticles}

The atomic force microscopy (AFM) images (Nanosurf Easy Scan 2 Basic AFM-pattern BT02217, Nanosurf Switzerland) were obtained using the cantilevers TapAl-G (BudgetSensors "Bulgaria) to scan the samples, in the contact mode. The nanoparticles of CS/TPP and SLN were previously diluted in the proportion of 1:100 and 1:1000 respectively. Samples were added to the grids and dried at room temperature for further analysis.

Nanoparticle size and PDI was determined by photon correlation spectroscopy (DLS), using a ZS90 analyzer (Malvern Instruments, UK) operated at $25^{\circ} \mathrm{C}$ and a fixed angle of $90^{\circ}$. The CS/TPP samples were analyzed directly, and a dilution of 1:100 (v: v) was used for the SLN. All samples were analyzed in triplicate.

The size distribution was also determined, together the concentration of the nanoparticles, by nanoparticle tracking analysis (NTA) (Model LM-10 analyzer, Malvern Instruments, UK), with the CS/TPP and SLN samples diluted in deionized water at ratios of 1:100 and 1:1000 (v: v), respectively. Each sample was measured five times, with approximately 4000 particles counted per analysis. The measurements were performed at $25^{\circ} \mathrm{C}$.

The zeta potential analyses were performed using the Malvern Instruments ZS90 analyzer, with direct analysis of the CS/TPP nanoparticles and dilution at 1:100 (v: v) in the case of the SLN. All samples were analyzed in triplicate. During the tests, the $\mathrm{pH}$ was measured using a potentiometer (Tecnal) coupled to a $\mathrm{pH}$ electrode.

\subsubsection{Evaluation of phytotoxicity}

The phytotoxicity of the CS/TPP and SLN nanoparticles were evaluated using three plant species: Zea mays L. (Poaceae), Brassica rapa L. (Brassicaceae), and Pisum sativum L. (Fabaceae). These species are recommended by United States Environmental Protection Agency phytotoxicity assays (US EPA, 1996; Ma et al., 2010). The seeds were previously treated in sodium hypochlorite solution (2.5\%) for $10 \mathrm{~min}$ and then washed three times with ultrapure water. Aqueous solutions of the nanoparticles $(10 \mathrm{~mL})$ were added to Petri plates $(100 \times 15 \mathrm{~mm})$. The stock solutions of CS/TPP and SLN nanoparticles (the nanoparticle solution after its prepare) were tested, as well as dilutions of stock solutions in water (of $75 \%, 50 \%$ and $25 \%$ ). Controls were performed using ultrapure water, PVA $(0.6 \%)$ and TPP $(0.1 \%)$. PVA and TPP were evaluated at the same concentrations they are found in the stock solution of nanoparticles. The incubation of seeds followed the procedure of Ma et al. (2010) with modifications. Basically, the Petri plates were covered and sealed with tape and placed in the dark for 6 days in a growth chamber at room temperature. Filter paper was not used in the base of Petri plates in order to prevent the interaction of this material with the nanoparticles. The assays were performed in triplicate, and each Petri plate contained 10 seeds per analysis. Seed germination was evaluated after six days of exposure to the nanoparticles, using Eq. (1):

Germination $(\%)=($ Number of germinated seeds $/ T S) \times 100$

Where $\boldsymbol{T S}$ is the total number of seeds used in the assay. A seed was considered as germinated when it presented a protruded radicle with more than $1 \mathrm{~mm}$ in length. In order to assess the early development of plantlets, the length of primary roots (bigger than $1 \mathrm{~mm}$ ) and shoots were measured. In the case of $Z$. mays, shoot was measured from root junction until the coleoptile apex. For $B$. rapa shoot measurement was from the hypocotyl base until the apex of the cotyledons, while for $P$. sativum it was from the epicotyl base until the leaf primordia. One-way analysis of variance (ANOVA) with Tukey's post-hoc test and significance level of 0.05 was used to determine the effects of the CS/TPP and SLN nanoparticles on the different plant species. Data was presented in the form of means and standard deviations. All the statistical procedures were performed using Graphpad Prism v. 5.01 software.

\section{Results and discussion}

\subsection{Characterization of the CS/TPP nanoparticles and SLN (Initial time assay)}

The nanoparticles were characterized using the DLS, NTA and AFM techniques. The size distribution plots (Fig. 1) revealed high polydispersity of the CS/TPP nanoparticles, indicative of different populations of nanoparticles, with a concentration of $1.33 \times 10^{10}$ nanoparticles $\mathrm{mL}^{-1}$. In the case of the SLN, there was a more homogeneous population of nanoparticles, with a concentration of $3.64 \times 10^{12}$ nanoparticles $\mathrm{mL}^{-1}$. As shown by AFM, both nanoparticles have 

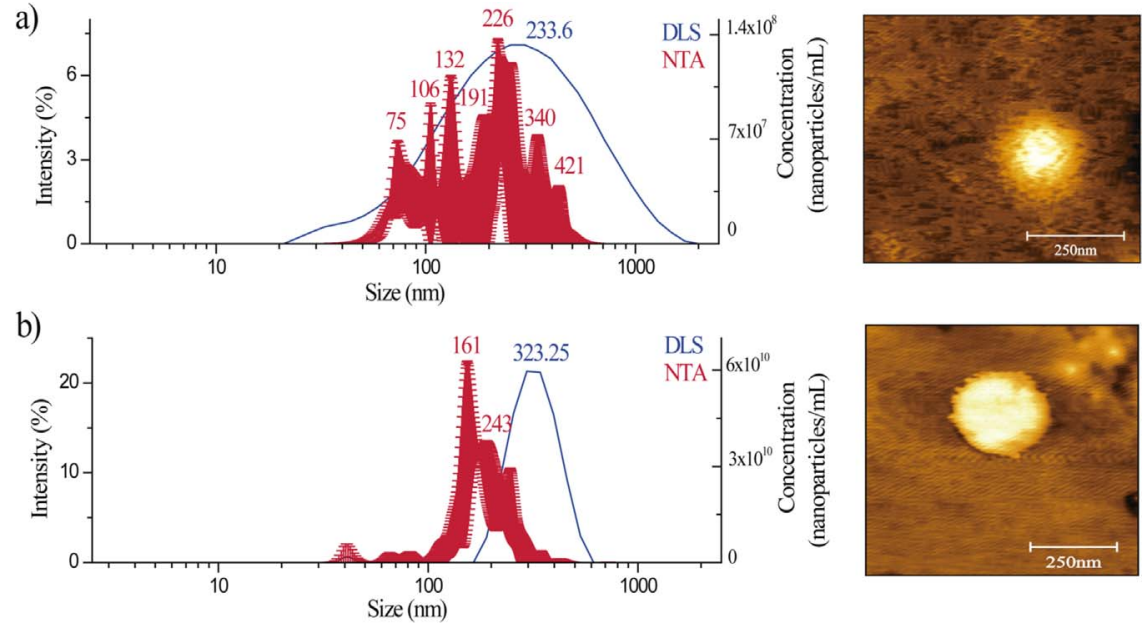

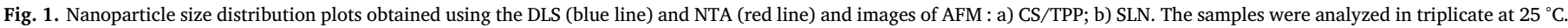

spherical shape. The characterization of the nanoparticles by DLS showed that the CS/TPP nanoparticles presented a size of $233.6 \pm 12.1 \mathrm{~nm}$, polydispersity index (PDI) of $0.30 \pm 0.02$, zeta potential of $+21.4 \pm 1.7 \mathrm{mV}$, and $\mathrm{pH}$ of $4.75 \pm 0.09$. These results were consistent with the size data obtained using NTA, where the majority of the nanoparticles showed an average size of $227.2 \pm 19.9 \mathrm{~nm}$ and high polydispersity. For the SLN, the DLS analyses showed an average size of $323.25 \pm 41.4 \mathrm{~nm}$, PDI of $0.23 \pm 0.103$, zeta potential of $-13 \mathrm{mV} \pm 3.2 \mathrm{mV}$, and $\mathrm{pH}$ of $4.69 \pm 0.21$. The average size obtained using NTA was $161 \mathrm{~nm}$, smaller than obtained using DLS.

Miladi et al. (2015) found that the sizes of CS/TPP nanoparticles produced using ionotropic gelation were usually smaller than $250 \mathrm{~nm}$, while under optimized conditions the particles obtained were in the 91-175 nm size range. The PDI values obtained here for these nanoparticles were in agreement with values in the range 0.1-0.4 (Calvo et al., 1997; Fan et al., 2012). The size, polydispersity index, and zeta potential of the SLN obtained here were in accordance with values reported previously using the same preparation method (de Oliveira et al., 2015).

\subsection{Evaluation of phytotoxicity of CS/TPP nanoparticles and SLN}

The results obtained with the controls show that the experimental conditions did not affect seed germination, since the seedlings showed no symptoms of stress (Fig. 2) and the germination rates were high (around $80 \%$ for Zea mays, 73\% for Brassica rapa and 90\% for Pisum sativum).

Fig. 2 shows the effects of the CS/TPP and SLN nanoparticles on the germination percentage for the different plant species The CS/TPP nanoparticles showed dose-dependent inhibitory effects on the germination of all tested species. B. rapa was the most sensitive one, with a complete inhibition of germination in the presence of $6.65 \times 10^{9}$ nanoparticles $\mathrm{mL}^{-1}$. No germination of $Z$. mays seeds was observed only at $1.33 \times 10^{10}$ nanoparticles $\mathrm{mL}^{-1}$, while the germination of $P$. sativum was reduced by $77.7 \%$ at the same concentration. The TPP polymer did not have any significant effects on the germination of the tested species. In the case of the SLN (Fig. 2), no inhibition of germination (relative to the control) was observed in the analyzed species, within the concentration range studied. It is noteworthy that this lack of effect was observed despite the seeds were exposed to higher concentrations of SLN in comparison with CS/TPP nanoparticles. This seemed to be indicative of differences between the SLN and CS/ TPP nanoparticles in terms of their interaction with the seeds.

As a result of the inhibitory effect on germination, the CS/TPP nanoparticles significantly affected the lenght of the root and shoot of $Z$. mays, with $82.3 \%$ reduction in development of roots and $94.6 \%$ for shoots by $9.98 \times 10^{9}$ nanoparticles $\mathrm{mL}^{-1}$, while higher concentrations of nanoparticles caused a complete cessation of development of these plant organs (Fig. 3). The same $100 \%$ inhibition was observed for $B$. rapa using nanoparticle concentrations of $6.65 \times 10^{9}, 9.98 \times 10^{9}$, and $1.33 \times 10^{10} \mathrm{~mL}^{-1}$, which is a consequence of the complete inhibition of germination in these conditions. For $P$. sativum $1.33 \times 10^{10}$ nanoparticles $\mathrm{mL}^{-1}$ negatively affected the development of the root and shoot by $80.3 \%$ and $95.2 \%$, respectively. In the case of B. rapa, nearly $81 \%$ reduction of root and shoot lenght was observed even at $3.33 \times 10^{9}$ nanoparticles $\mathrm{mL}^{-1}$, a concentration that did not affect germination, suggesting that a direct effect of CS/TPP nanoparticles on the early development of seedlings of this species may occur. For all controls with TPP, there was no inhibitory effect on root and shoot lenght, showing that the observed effects can be attributed to the nanoparticles. Fig. 3 also shows that root and shoot length of all species were not affected by any treatments with SLN or with PVA.

Although not tested separately in the present study, it is known that the CS polymer is nontoxic and for this reason has considerable potential for applications in agriculture, where it can act as a biostimulant and/or reduce abiotic stress in plants, as well as increase resistance against pathogens (Pichyangkura and Chadchawan, 2015). According to this, in recent studies of our group, different CS-based nanoparticles have been shown to not impair germination and initial growth of Phaseolus vulgaris (Pereira et al., 2017a, 2017b). Regarding the acetic acid, the concentration present in the CS/TPP nanoparticles is $0.038 \mathrm{mM}$, and as described in literature the phytotoxic effects of acetic acid on seeds are observed in concentration higher than $4 \mathrm{mM}$ (Tunes et al., 2012). Moreover, CS/ $\gamma$-polyglutamic acid nanoparticles, in which acetic acid was present at $0.15 \mathrm{mM}$, did not have phytotoxic effects against $P$. vulgaris (Pereira et al., 2017a). Thus, in the present study, the inhibitory action of the CS/TPP nanoparticles on germination could have been a result of the different properties exhibited by materials at the nanometric scale, and not due to the isolated materials per se. Many factors are probably involved in the distinct phytotoxicity of CS/TPP nanoparticles and SLN. Characteristics such as size, concentration, reactivity, chemical structure and surface charge may determine the effects that nanoparticles cause in plants (Rico et al., 2011; Tripathi et al., 2017). Here, concentration is not involved, given that SLN concentrations in the assays were higher than CS/TPP ones. However, size may be an important factor, since CS/TPP nanoparticles $(233.0 \pm 12.1 \mathrm{~nm})$ are smaller than SLN $(323.3 \pm 41.4 \mathrm{~nm})$. In animal cells, it is known that nanoparticle internalization and toxicity is negatively correlated with nanoparticle size (Shang et al., 2014).

Surface charge may be an additional characteristic that affects nanoparticle phytotoxicity (Tripathi et al., 2017). According to Trujillo- 

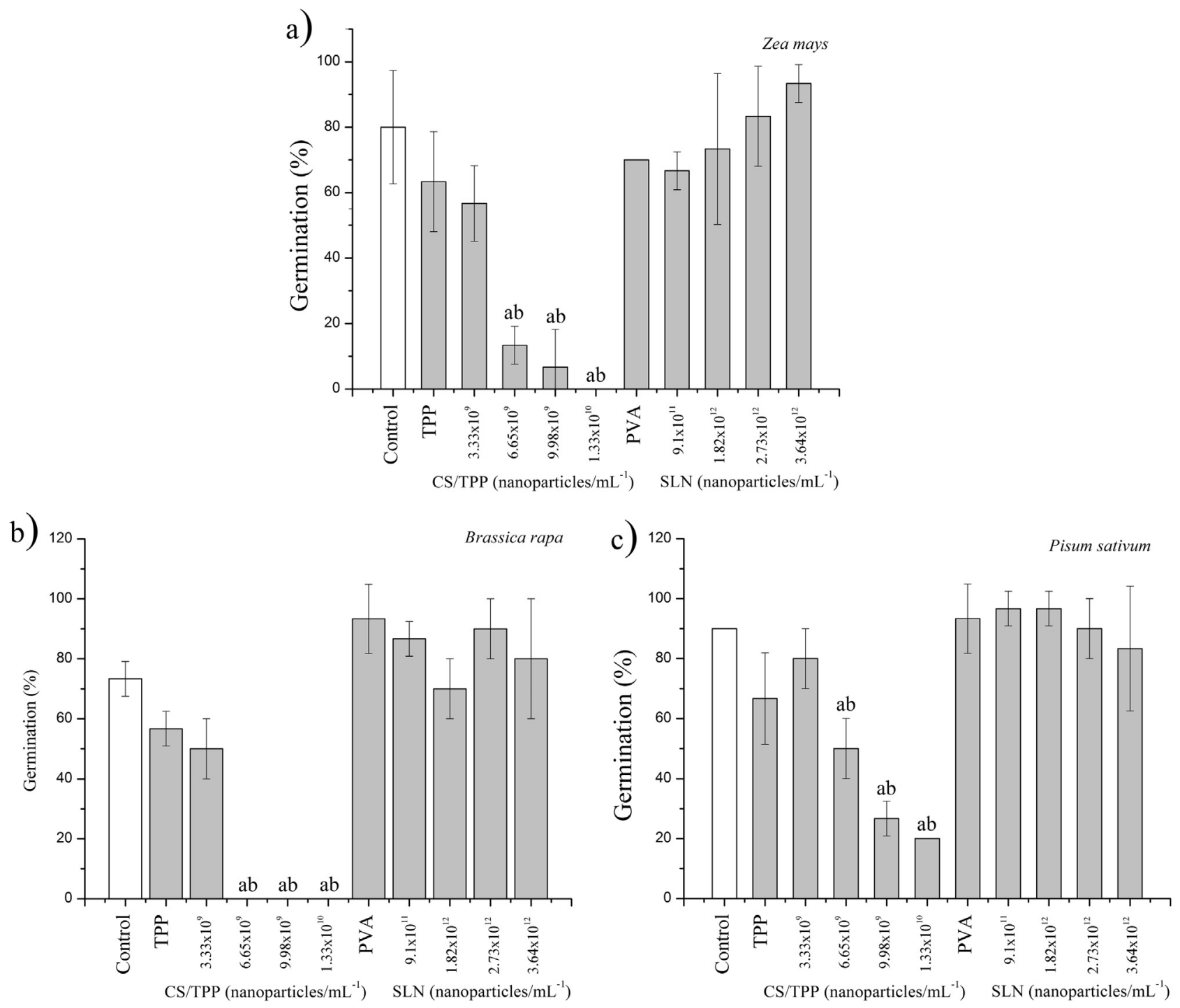

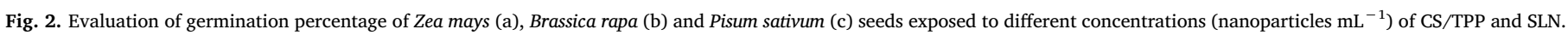

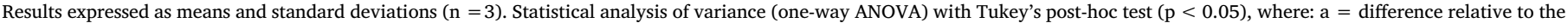
control; $\mathrm{b}=$ difference relative to the TPP polymer (CS/TPP formulations) or the PVA surfactant (SLN formulations).

Reyes et al. (2013), the uptake of cerium nanoparticles (zeta potential $=+21 \mathrm{mV}$ ) by plants was higher than that of the same nanoparticles covered with citric acid (zeta potential $=-56 \mathrm{mV}$ ). Moreover, alterations in the surface of aluminum nanoparticles led to changes in the phytotoxicity response (Yang and Watts, 2005). In the present study, CS/TPP nanoparticles had a zeta potential of $+21.4 \mathrm{mV}$, whereas SLN had a negative zeta potential $(-13.3 \mathrm{mV})$ and it can be hypothesized whether these distinct characteristics might related with their phytotoxicity responses. The absence of phytotoxic effects of SLN may be related to the negative charge of these nanoparticles, which would prevent their interaction with carboxyl groups of pectin in the plant cell wall (Anderson, 2016). Differently, the positive charge of CS/TPP nanoparticles would favor their interaction with plant cell wall, thus leading to inhibitory effects of these nanoparticles on germination and plant growth (Figs. 2 and 3).

Various studies have shown that nanoparticles can penetrate the cell walls in plant roots, becoming internalized in the cells and/or reaching the vascular system of the plant and being distributed to other plant organs such as the stem, leaves, and fruit (Pérez-de-Luque et al., 2012; Wang et al., 2012). Chen et al. (2010) investigated the effects of carbon nanotubes on $A$. cepa and found that larger and more hydrophobic particles could create barriers in the pores of the cell walls, affecting the physiological state of the plant and leading to cell damage. Zhao et al. (2015) reported that exposure of Zea mays to zinc oxide nanoparticles altered the physiological and biochemical processes of the plant during its maturation cycle, reducing stomatal conductance and photosynthesis, with consequent reduction of leaf weight. Ma et al. (2015) found that cerium nanoparticles with different shapes and sizes were taken up and accumulated by plants at different rates, causing differing degrees of oxidative stress. The various mechanisms described above could have contributed to the phytotoxic effects of the CS/TPP nanoparticles on the plant species evaluated here, although methods are required to establish relationships between the uptake of the particles by the plant and the biological effects. It should be highlighted that the nature of chitosan nanoparticles (carbohydrates) and SLN (lipids) makes them extremely difficult to track these nanoparticles in plants, compared to metal and metal oxide nanoparticles, or even carbon nanotubes.

In other studies of the herbicidal activity of carrier systems, de Oliveira et al. (2015) evaluated the effects of SLN and the herbicides simazine and atrazine, finding that pre- and post-emergence treatment of Zea mays with nanoparticles alone (without the herbicides) did not induce any phytotoxic effects. Differently, at the highest concentration tested, pre-emergence treatment of Raphanus raphanistrum led to decreased fresh weights of the roots and shoots, although such effects 

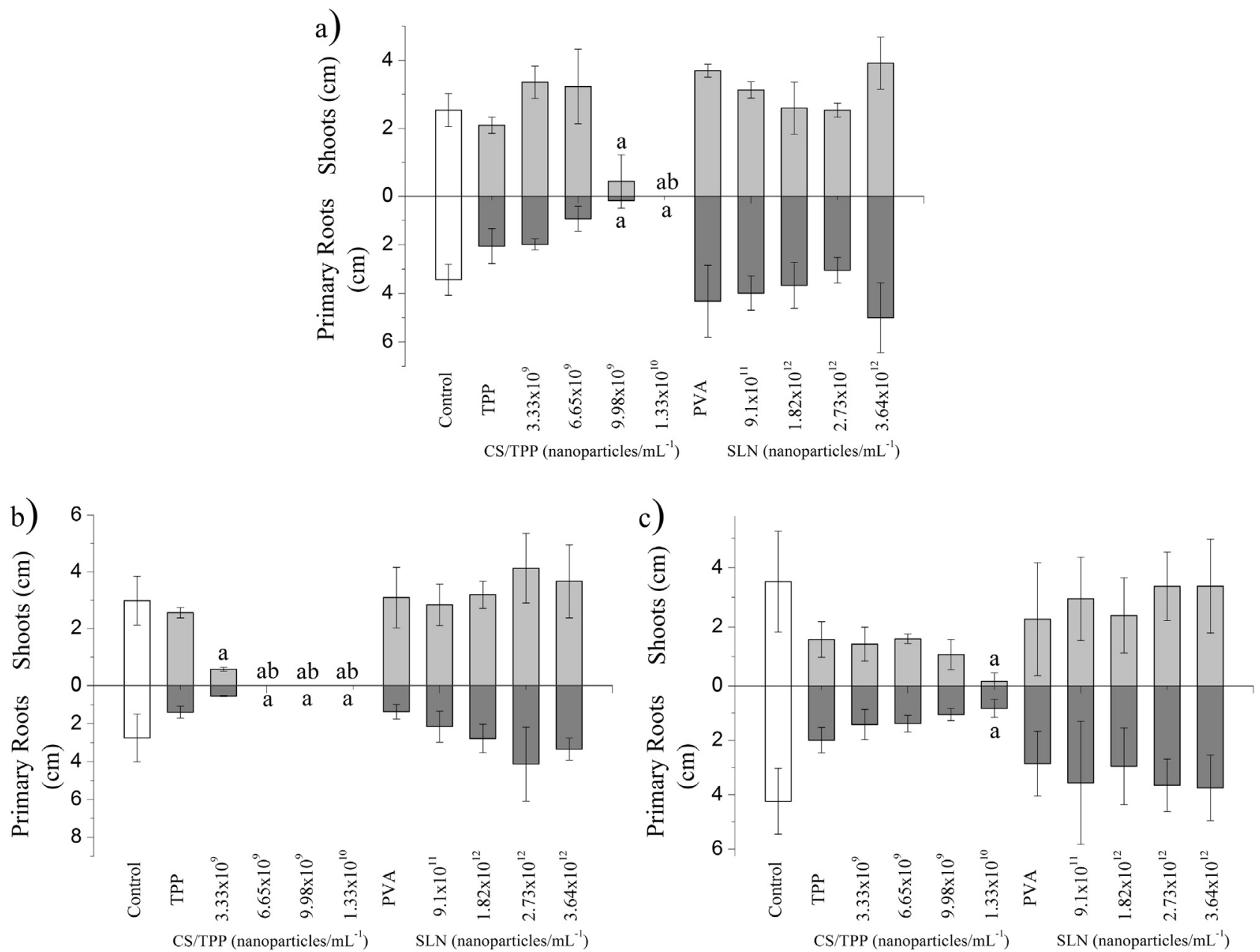

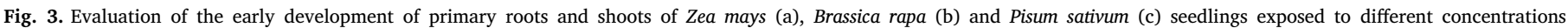

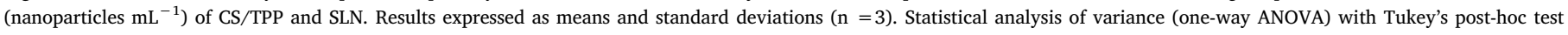
( $\mathrm{p}<0.05$ ), where: $\mathrm{a}=$ difference relative to the control; $\mathrm{b}=$ difference relative to the TPP polymer (CS/TPP formulations) or the PVA surfactant (SLN formulations).

were not observed in the case of post-emergence treatment. In work with the poly(epsilon-caprolactone) nanocapsules as carrier system of atrazine, pre-emergence treatment of Brassica sp. using nanocapsules without herbicide led to inhibition of germination (Pereira et al., 2014). Oliveira et al. (2015a) showed that the post-emergence treatment of Brassica juncea with the same nanocapsules in the absence of the herbicide did not cause symptoms of phytotoxicity in the leaves, did not affect plant growth, and did not influence biochemical and physiological parameters. The same results were obtained for pre- and postemergence treatment of Zea mays (Oliveira et al., 2015b).

In the preparation of nanoparticle formulations, it is considered the concentration of active chemical and not the concentration of nanoparticles, as shown in this study, high concentration of nanoparticles (stock solution) of CS/TPP inhibited germination and plant growth. These results should be considered for the establishment of safe concentrations of these nanoformulations in future studies evaluating the potential application of these carrier systems in the agriculture, thereby avoiding damage to both target and non-target plants and to the environment.

In the present work, the CS/TPP nanoparticles were smaller than the SLN, which together with the different compositions and the opposite charges could have led to the different effects on the plant species studied. In the case of the CS/TPP nanoparticles, the induction of phytotoxicity in the plant species could have been associated with the interaction of the positive-charged nanoparticles with the cell wall, forming of a barrier. It would lead to reduction of germination and root and shoot lenght, as well as physiological and biochemical responses following internalization, which resulted in low germination rates and compromised plant development. However, further studies are needed to understand the mechanisms of interaction and phytotoxicity of these particles in plants.

\section{Conclusions}

This work describes the effects of polymeric CS/TPP and SLN nanoparticles at different concentrations on the germination and root and shoot lenght of the plant species Zea mays, Brassica rapa, and Pisum sativum. The CS/TPP nanoparticles were smaller in size, compared to the SLN, which together with the opposite charges and different compositions resulted in different responses in the species tested. The CS/TPP nanoparticles showed phytotoxicity that was dependent on concentration, while the SLNs showed no phytotoxic effects in any species. Various studies have reported the effects of different nanomaterials on plants, but little is known about the physiological and biochemical mechanisms involved, and further studies are needed to understand the mechanisms of interaction between nanoparticulate materials and plants. The present study demonstrates the importance of phytotoxicity evaluation of the effects of polymeric nanoparticles in plants, especially because these materials have considerable potential for application as carrier systems in agriculture. In the case of carrier systems that have direct application to seeds or other plant structures, the concentration and type of nanoparticle to be used should be considered to avoid unwanted phytotoxic effects. It is therefore necessary to establish safe concentrations for the application of 
nanoparticles, ensuring that these materials have the desired effects, without affecting both target and non-target plants and other organisms. It should be pointed out that further trials are in progress aiming at better understanding of the possible mechanisms of interaction between these nanoparticles and plants. The strategies employed include the use of fluorescent probes and hybrid systems consisting of polymeric and magnetic nanoparticles.

\section{Acknowledgments}

The authors are grateful for the financial support provided by the São Paulo State Science Foundation (FAPESP, grants \#2013/12322-2 and \#2015/15617-9) and CNPq. A.E.S.P. received a PhD scholarship from CNPq (grants \#140849/2013-9).

\section{References}

Anderson, C.T., 2016. We be jammin': an update on pectin biosynthesis, trafficking and dynamics. J. Exp. Bot. 67, 495-502. http://dx.doi.org/10.1093/jxb/erv501.

Calvo, P., Remuñán-López, C., Vila-Jato, J.L., Alonso, M.J., 1997. Novel hydrophilic chitosan-polyethylene oxide nanoparticles as protein carriers. J. Appl. Polym. Sci. 63, 125-132. http://dx.doi.org/10.1002/(SICI)1097-4628(19970103)63:1 <125::AIDAPP13 > 3.0.CO;2-4.

Campos, E.V.R., Oliveira, J.L., de, Fraceto, L.F., Singh, B., 2014. Polysaccharides as safer release systems for agrochemicals. Agron. Sustain. Dev. 35, 47-66. http://dx.doi.org/ 10.1007/s13593-014-0263-0.

Chen, R., Ratnikova, T.A., Stone, M.B., Lin, S., Lard, M., Huang, G., Hudson, J.S., Ke, P.C., 2010. Differential Uptake of Carbon Nanoparticles by Plant and Mammalian Cells. Small 6, 612-617. http://dx.doi.org/10.1002/smll.200901911.

de Oliveira, J.L., Campos, E.V.R., Gonçalves da Silva, C.M., Pasquoto, T., Lima, R., Fraceto, L.F., 2015. Solid Lipid Nanoparticles Co-loaded with Simazine and Atrazine: Preparation, Characterization, and Evaluation of Herbicidal Activity. J. Agric. Food Chem. 63, 422-432. http://dx.doi.org/10.1021/jf5059045.

Environmental Protection Agency (US EPA), 1996. Ecological effects test guidelines. OPPTS850.4150 Terrestrial Plant Toxicity, Tier I (vegetative Vigor). EPA 712-C-96163.Public Draft. Office of Prevention, Pesticides and Toxic Substances, Washington DC.

Fan, W., Yan, W., Xu, Z., Ni, H., 2012. Formation mechanism of monodisperse, low molecular weight chitosan nanoparticles by ionic gelation technique. Colloids Surf. B Biointerfaces 90, 21-27. http://dx.doi.org/10.1016/j.colsurfb.2011.09.042.

Husen, A., Siddiqi, K.S., 2014. Carbon and fullerene nanomaterials in plant system. J. Nanobiotechnology 12, 16. http://dx.doi.org/10.1186/1477-3155-12-16.

Kashyap, P.L., Xiang, X., Heiden, P., 2015. Chitosan nanoparticle based delivery systems for sustainable agriculture. Int. J. Biol. Macromol. 77, 36-51. http://dx.doi.org/10. 1016/j.ijbiomac.2015.02.039.

Khodakovskaya, M., Dervishi, E., Mahmood, M., Xu, Y., Li, Z., Watanabe, F., Biris, A.S., 2009. Carbon nanotubes are able to penetrate plant seed coat and dramatically affect seed germination and plant growth. ACS Nano 3, 3221-3227. http://dx.doi.org/10. $1021 / \mathrm{nn} 900887 \mathrm{~m}$.

Larue, C., Castillo-Michel, H., Sobanska, S., Cécillon, L., Bureau, S., Barthès, V., Ouerdane, L., Carrière, M., Sarret, G., 2014. Foliar exposure of the crop Lactuca sativa to silver nanoparticles: evidence for internalization and changes in Ag speciation. J. Hazard. Mater. 264, 98-106. http://dx.doi.org/10.1016/j.jhazmat.2013.10.053.

Liu, R., Zhang, H., Lal, R., 2016. Effects of Stabilized Nanoparticles of Copper, Zinc, Manganese, and Iron Oxides in Low Concentrations on Lettuce (Lactuca sativa) Seed Germination: nanotoxicants or Nanonutrients? Water Air. Soil Pollut. 227, 1-14. http://dx.doi.org/10.1007/s11270-015-2738-2.

Ma, X., Geiser-Lee, J., Deng, Y., Kolmakov, A., 2010. Interactions between engineered nanoparticles (ENPs) and plants: phytotoxicity, uptake and accumulation. Sci. Total Environ. 408, 3053-3061. http://dx.doi.org/10.1016/j.scitotenv.2010.03.031.

Ma, X., Wang, Q., Rossi, L., Zhang, W., 2015. Cerium Oxide Nanoparticles and Bulk Cerium Oxide Leading to Different Physiological and Biochemical Responses in Brassica rapa. Environ. Sci. Technol. http://dx.doi.org/10.1021/acs.est.5b04111.

Ma, Y., Kuang, L., He, X., Bai, W., Ding, Y., Zhang, Z., Zhao, Y., Chai, Z., 2010. Effects of rare earth oxide nanoparticles on root elongation of plants. Chemosphere 78 , 273-279. http://dx.doi.org/10.1016/j.chemosphere.2009.10.050.

Miladi, K., Sfar, S., Fessi, H., Elaissari, A., 2015. Enhancement of alendronate encapsulation in chitosan nanoparticles. J. Drug Deliv. Sci. Technol., Honor Prof. Dominique Duchêne 30, Part B 391-396. http://dx.doi.org/10.1016/j.jddst.2015.04. 007.

Oliveira, H.C., Stolf-Moreira, R., Martinez, C.B.R., Grillo, R., de Jesus, M.B., Fraceto, L.F., 2015a. Nanoencapsulation Enhances the Post-Emergence Herbicidal Activity of Atrazine against Mustard Plants. PLoS ONE 10. http://dx.doi.org/10.1371/journal. pone. 0132971 .

Oliveira, H.C., Stolf-Moreira, R., Martinez, C.B., Sousa, G.F.M., Grillo, R., de Jesus, M.B.,
Fraceto, L.F., 2015b. Evaluation of the side effects of poly(epsilon-caprolactone) nanocapsules containing atrazine toward maize plants. Front. Chem. 3, 61. http://dx. doi.org/10.3389/fchem.2015.00061.

Part, F., Zecha, G., Causon, T., Sinner, E.-K., Huber-Humer, M., 2015. Current limitations and challenges in nanowaste detection, characterisation and monitoring. Waste Manag. 43, 407-420. http://dx.doi.org/10.1016/j.wasman.2015.05.035.

Pereira, A.E.S., Grillo, R., Mello, N.F.S., Rosa, A.H., Fraceto, L.F., 2014. Application of poly(epsilon-caprolactone) nanoparticles containing atrazine herbicide as an alternative technique to control weeds and reduce damage to the environment. J. Hazard. Mater. 268, 207-215. http://dx.doi.org/10.1016/j.jhazmat.2014.01.025.

Pereira, A.E., Sandoval-Herrera, I.E., Zavala-Betancourt, S.A., Oliveira, H.C., LedezmaPérez, A.S., Romero, J., Fraceto, L.F., 2017a. $\gamma$-Polyglutamic acid/chitosan nanoparticles for the plant growth regulator gibberellic acid: characterization and evaluation of biological activity. Carbohydr. Polym. 157, 1862-1873. http://dx.doi. org/10.1016/j.carbpol.2016.11.073.

Pereira, A.E.S., Silva, P.M., Oliveira, J.L., Oliveira, H.C., Fraceto, L.F., 2017b. Chitosan nanoparticles as carrier systems for the plant growth hormone gibberellic acid. Colloids Surf. B Biointerfaces 150, 141-152. http://dx.doi.org/10.1016/j.colsurfb. 2016.11.027.

Pérez-de-Luque, A., Cifuentes, Z., Marquina, C., Jesús, M., Ibarra, M.R., 2012. Synthesis, Application, and Tracking of Magnetic Carbon-Coated Nanoparticles in Plants Nanoparticles in Biology and Medicine. In: Springer, pp. 263-272.

Pichyangkura, R., Chadchawan, S., 2015. Biostimulant activity of chitosan in horticulture. Sci. Hortic., Biostimulants Hortic. 196, 49-65. http://dx.doi.org/10. 1016/j.scienta.2015.09.031.

Rajeshwari, A., Kavitha, S., Alex, S.A., Kumar, D., Mukherjee, A., Chandrasekaran, N., Mukherjee, A., 2015. Cytotoxicity of aluminum oxide nanoparticles on Allium cepa root tip-effects of oxidative stress generation and biouptake. Environ. Sci. Pollut. Res. 22, 11057-11066. http://dx.doi.org/10.1007/s11356-015-4355-4.

Rico, C.M., Majumdar, S., Duarte-Gardea, M., Peralta-Videa, J.R., Gardea-Torresdey, J.L., 2011. Interaction of Nanoparticles with Edible Plants and Their Possible Implications in the Food Chain. J. Agric. Food Chem. 59, 3485-3498. http://dx.doi.org/10.1021/ jf104517j.

Servin, A., Elmer, W., Mukherjee, A., Torre-Roche, R.D., la, Hamdi, H., White, J.C., Bindraban, P., Dimkpa, C., 2015. A review of the use of engineered nanomaterials to suppress plant disease and enhance crop yield. J. Nanopart. Res. 17, 1-21. http://dx. doi.org/10.1007/s11051-015-2907-7.

Servin, A.D., Castillo-Michel, H., Hernandez-Viezcas, J.A., Diaz, B.C., Peralta-Videa, J.R., Gardea-Torresdey, J.L., 2012. Synchrotron Micro-XRF and Micro-XANES Confirmation of the Uptake and Translocation of TiO2 Nanoparticles in Cucumber (Cucumis sativus) Plants. Environ. Sci. Technol. 46, 7637-7643. http://dx.doi.org/ 10.1021/es300955b.

Shang, L., Nienhaus, K., Nienhaus, G.U., 2014. Engineered nanoparticles interacting with cells: size matters. J. Nanobiotechnology 12, 5. http://dx.doi.org/10.1186/14773155-12-5.

Thuesombat, P., Hannongbua, S., Akasit, S., Chadchawan, S., 2014. Effect of silver nanoparticles on rice (Oryza sativa L. cv. KDML 105) seed germination and seedling growth. Ecotoxicol. Environ. Saf. 104, 302-309. http://dx.doi.org/10.1016/j.ecoenv. 2014.03.022.

Tripathi, D.K., Shweta, Singh, S., Singh, S., Pandey, R., Singh, V.P., Sharma, N.C., Prasad, S.M., Dubey, N.K., Chauhan, D.K., 2017. An overview on manufactured nanoparticles in plants: uptake, translocation, accumulation and phytotoxicity. Plant Physiol. Biochem. Eff. Nanomater. Plants 110, 2-12. http://dx.doi.org/10.1016/j.plaphy. 2016.07.030.

Trujillo-Reyes, J., Vilchis-Nestor, A.R., Majumdar, S., Peralta-Videa, J.R., GardeaTorresdey, J.L., 2013. Citric acid modifies surface properties of commercial CeO2 nanoparticles reducing their toxicity and cerium uptake in radish (Raphanus sativus) seedlings. J. Hazard. Mater. 263, Part 2, 677-684. http://dx.doi.org/10.1016/j. jhazmat.2013.10.030.

Tunes, L.M., de, Avelar, S.A.G., Barros, A.C.S.A., Pedroso, D.C., Muniz, M.F.B., Menezes, N.L. de, 2012. Critical levels of organic acids on seed germination and seedling growth of wheat. Rev. Bras. Sement-. 34, 366-372.

Vitorino, C., Carvalho, F.A., Almeida, A.J., Sousa, J.J., Pais, A.A.C.C., 2011. The size of solid lipid nanoparticles: an interpretation from experimental design. Colloids Surf. B Biointerfaces 84, 117-130. http://dx.doi.org/10.1016/j.colsurfb.2010.12.024.

Wang, X., Han, H., Liu, X., Gu, X., Chen, K., Lu, D., 2012. Multi-walled carbon nanotubes can enhance root elongation of wheat (Triticum aestivum) plants. J. Nanopart. Res. 14, 1-10. http://dx.doi.org/10.1007/s11051-012-0841-5.

Yang, L., Watts, D.J., 2005. Particle surface characteristics may play an important role in phytotoxicity of alumina nanoparticles. Toxicol. Lett. 158, 122-132. http://dx.doi. org/10.1016/j.toxlet.2005.03.003.

Zhao, L., Sun, Y., Hernandez-Viezcas, J.A., Hong, J., Majumdar, S., Niu, G., DuarteGardea, M., Peralta-Videa, J.R., Gardea-Torresdey, J.L., 2015. Monitoring the Environmental Effects of $\mathrm{CeO} 2$ and $\mathrm{ZnO}$ Nanoparticles Through the Life Cycle of Corn (Zea mays) Plants and in Situ $\mu$-XRF Mapping of Nutrients in Kernels. Environ. Sci. Technol. 49, 2921-2928. http://dx.doi.org/10.1021/es5060226.

Zhu, Z.-J., Wang, H., Yan, B., Zheng, H., Jiang, Y., Miranda, O.R., Rotello, V.M., Xing, B., Vachet, R.W., 2012. Effect of surface charge on the uptake and distribution of gold nanoparticles in four plant species. Environ. Sci. Technol. 46, 12391-12398. http:// dx.doi.org/10.1021/es301977w. 